\title{
O CONSTRUCTO ASSÉDIO MORAL NA RELAÇ̃̃O ALUNO-PROFESSOR NA PERSPECTIVA DE PROFESSORES UNIVERSITÁRIOS
}

E-mail: robertobrazileiro@gmail.com

\section{Daniel Reis Armond de Melo}

Professor Adjunto da Universidade Federal do Amazonas - Manaus-AM, Brasil

Doutor em Administração pela Universidade Federal da Bahia (UFBA)

E-mail: armond@ufam.edu.br

\section{Jader Cristiano de Souza-Silva}

Professor Titular B da Universidade do Estado da Bahia (UNEB- Salvador-BA, Brasil

Professor Titular do Mestrado em Administração da UNIFACS

Professor do Departamento de Administração da FAINOR

Doutor em Aprendizagem Organizacional (UFBA/Michigan State University)

E-mail: jadersouza@talentus4.com.br

\section{Jorge Santos Néris}

Professor Adjunto da Universidade Federal do Oeste da Bahia (UFOB) - Barreiras-

BA, Brasil

Doutor em Psicologia pela UFBA

E-mail: neris@ufob.edu.br

\section{RESUMO}

O objetivo geral deste artigo é contribuir para uma melhor compreensão do constructo assédio moral na relação aluno-professor. Tal conceito, de cunho geral, leva ao questionamento de como esse constructo é compreendido por professores universitários que o vivenciam em suas práticas de trabalho. No sentido de responder ao questionamento, foram realizadas 42 entrevistas com docentes universitários. Os dados coletados foram tabulados e organizados por meio da metodologia do Discurso do Sujeito Coletivo (DSC). Os resultados indicam seis discursos coletivos, que têm como ideias-chave: constrangimento ao professor, pressão para obter vantagens, falta de respeito, condutas difamatórias recorrentes, obstáculos ao propósito da docência e ameaça à integridade moral e física. O aprofundamento do entendimento do assédio moral na relação aluno-professor é relevante, pois contribui para uma maior consciência e reflexão sobre comportamentos destrutivos que não são mais aceitáveis no estágio evolutivo da sociedade moderna e, sobretudo, que ainda ocorrem em um grupo social no qual se propõe precipuamente formar cidadãos socialmente responsáveis e moralmente íntegros.

Palavras-chave: Assédio Moral, Ensino Superior, Relação Aluno-Professor, Discurso do Sujeito Coletivo. 


\section{THE MOBBING CONSTRUCT IN STUDENT-TEACHER RELATIONSHIP FROM THE PERSPECTIVE OF UNIVERSITY PROFESSORS}

\section{ABSTRACT}

The general purpose of this paper is to contribute to a better understanding of the construct mobbing in professor-student relationship. This concept, of general nature, leads to the question of how this construct is understood by university professors who experience it in their working practices. In order to answer the question, 42 interviews were conducted with university professors. The collected data were tabulated and organized through the methodology of the Collective Subject Discourse (CSD). The results indicate six Collective Subject Discourses, whose key ideas are: embarrassment to the teacher, pressure to obtain benefits, disrespectfulness, recurring defamatory behavior, obstacles to the purpose of teaching and threat to moral and physical integrity. The deepening of the understanding of mobbing in the student-professor relationship is important because it contributes to an increased awareness and reflection on destructive behaviors that are no longer acceptable in the evolutionary stage of modern society and that, above all, still occur in a social group where the purpose is to educate socially responsible citizens and of morally integrity.

Key words: Mobbing, Higher Education, Student-Professor-Relationship, Collective Subject Discourse.

\section{EL CONSTRUCTO ACOSO MORAL EN LA RELACIÓN ALUMNO-PROFESOR EN LA PERSPECTIVA DE PROFESORES UNIVERSITARIOS}

\section{RESUMEN}

El objetivo general de este artículo es contribuir en el sentido de una mejor comprensión del constructo acoso moral en la relación alumno-profesor. Tal concepto, de carácter general, lleva al cuestionamiento de cómo ese constructo es comprendido por profesores universitarios que lo padecen en sus prácticas de trabajo. Con la intención de responder al cuestionamiento, fueron realizadas 42 entrevistas con docentes universitarios. Los datos recolectados fueron tabulados y organizados mediante la metodología del Discurso del Sujeto Colectivo (DSC). Los resultados indican seis discursos colectivos, que tienen como ideas-clave: avergonzar al profesor, presión para obtener ventajas, falta de respeto, conductas difamatorias recurrentes, obstáculos al propósito de la docencia y amenaza a la integridad moral y física. La profundización del entendimiento del acoso moral en la relación alumno-profesor es relevante, pues contribuye para una mayor conciencia y reflexión sobre comportamientos destructivos que no son más aceptables en la etapa evolutiva de la sociedad moderna y, sobretodo, que todavía ocurren en un grupo social en el cual se propone principalmente formar ciudadanos socialmente responsables y moralmente integros.

Palabras-llave: Acoso Moral, Enseñanza Superior, Relación Alumno-Profesor, Discurso del Sujeto Colectivo. 


\section{INTRODUÇÃO}

Pesquisas demonstram que grande parte dos professores universitários possui alto nível de satisfação laboral em razão da natureza de seu trabalho (SORCINELLI, 1994). Tal satisfação ocorre, dentre outros aspectos, porque o trabalho acadêmico oferece significativa autonomia, constitui-se em caminho interessante para $\mathrm{o}$ desenvolvimento intelectual, contribui positivamente na vida de outras pessoas, além de promover rápido sentimento de realização (OLSEN; SORCINELLI, 1992; SORCINELLI, 1994; SORCINELLI; AUSTIN, 2010; SADLER, 2012).

Apesar desses sentimentos de satisfação e de realização, nem tudo são flores na profissão do professor. São muitos, também, os aspectos que perturbam o dia a dia dos docentes universitários. Tensão, pressão, ansiedade, angústia e preocupação são emoções que acompanham a labuta cotidiana dos profissionais da educação superior (FINK, 1984; TURNER; BOICE, 1987; SADLER, 2012).

A literatura internacional aponta alguns fatores que têm contribuído para esses tipos de emoções que acompanham a carreira docente: tempo reduzido para pesquisa e preparação das aulas, falta de tempo para se relacionar e trocar experiências com outros professores, ausência de feedback, carência de reconhecimento e de recompensa e dificuldades de equilíbrio entre a vida pessoal e a profissional (SORCINELLI, 1994; SORCINELLI; AUSTIN, 2010).

No Brasil, essa realidade não é diferente. Agrava-se mais ainda quando consideramos o cenário de expansão do ensino superior público, com grande elevação na oferta de vagas, e também de expansão do ensino superior privado, marcado por orientações substancialmente mercantilistas (SOUZA-SILVA; DAVEL, 2005).

Notadamente no cenário privado, os valores educacionais podem se prostituir, trazendo uma série de malefícios nas relações que permeiam o processo de ensino-aprendizagem. Um desses malefícios, por exemplo, é o estudante ser visto como um cliente que jamais deve ser contrariado. Para não aborrecê-lo, o processo educacional é banalizado. O professor facilita as avaliações, não exige um bom desempenho, como deveria, vulgarizando sua atuação. É a concepção de buscar satisfazer o aluno a qualquer custo, pois ele é uma fonte de lucro (SOUZA-SILVA; DAVEL, 2005). Pratica-se, assim, a máxima do finge-se que se ensina e finge-se que se aprende. A consequência disso é a aprovação dos alunos nas disciplinas sem que eles apresentem qualquer proficiência nelas. No ensino superior público, apesar de não haver a visão clientelista, o alunado se posiciona em relação à obrigação do Estado pela educação, muitas vezes de uma maneira ríspida, sob a forma consumista, afetando principalmente o professor, seu interlocutor imediato. Além disso, o poder do professor é instituído de forma superficial, visto que sua autoridade muitas vezes não se configura (SENNET, 2009).

Nesse sentido, o papel do professor acaba sendo menosprezado e desvalorizado. O problema não para por aí. $\mathrm{Na}$ busca incessante de satisfazer o aluno de qualquer forma, os valores se degradam e os desmandos e excessos ocorrem. É nesse contexto que acontecem as atitudes desrespeitosas na relação aluno-professor, culminando no assédio moral (AM).

O assédio moral na relação aluno-professor acontece quando a concepção do aluno-cliente é enfatizada e quando os valores essenciais que permeiam a educação são esquecidos e desvalorizados. Assim, o professor acaba se submetendo a situações de constrangimento moral e se afasta de seus papéis educacionais mais essenciais. Descaracteriza-se o processo educativo e desmoraliza-se a figura do professor.

Nesse contexto, o objetivo deste artigo é buscar compreender o constructo assédio moral do aluno para com o professor. De forma complementar, tem-se o intuito de identificar os tipos de assédio que estariam presentes nessa relação peculiar, a partir de informações obtidas por quem poderia ser vítima da ação ilícita, o professor universitário. Espera-se, com a presente pesquisa, contribuir para os estudos sobre assédio moral, mas com a especificidade de análise do vetor discente-docente, relevante fundamentalmente pelo atual contexto do ensino superior no Brasil e no mundo, mas também pela 
carência de pesquisas nesta linha. Enquanto Paixão et al. (2013) concentraram a análise na ocorrência e no trato do assédio moral na relação aluno-professor, esta pesquisa mantém o enfoque no entendimento do constructo envolvido.

O presente artigo está estruturado em cinco seções, incluindo esta introdução. $\mathrm{Na}$ segunda seção, é apresentado o referencial teórico que serve de suporte à pesquisa, com ênfase na conceituação do assédio moral e de seus tipos e na apresentação de estudos envolvendo alunos e professores. Em seguida, na terceira seção, expõese o método utilizado, o discurso do sujeito coletivo, de cunho qualiquantitativo, além da descrição dos procedimentos metodológicos. $\mathrm{Na}$ quarta seção são apresentadas as análises obtidas a partir dos dados coletados, bem como a confrontação dos mesmos com o referencial teórico. Por fim, na quinta seção são tecidas considerações finais acerca da pesquisa, de suas contribuições e limitações, e feitas sugestões para novos estudos.

\section{REFERENCIAL TEÓRICO}

\subsection{Conceitos de Assédio Moral}

O assédio moral (AM) apresenta-se sob muitas expressões, a depender do país analisado; tem, porém, basicamente, um único significado. Acoso moral (Portugal), mobbing (EUA), bulling (Inglaterra), harcèlement moral (França) e ijime (Japão) são exemplos de expressões para o assédio moral. Todas elas expressam um descumprimento das regras de trato social definidas pela sociedade e cuja sanção é difícil por ser difusa sua ocorrência (FIUZA, 2004; VEGA; COMER, 2005).

O termo assédio expressa o sentido de insistência inconveniente, certa perseguição em relação a outrem. Já o termo moral está relacionado com os princípios ou valores que norteiam as relações, o agir e o pensar dos indivíduos. Assim, analisando especificamente o aspecto linguístico do termo, percebe-se que o AM constitui uma ação com implicação moral. No entender de Santos (2005), o AM está consubstanciado na coação, no constrangimento ou na perseguição recorrente dos princípios e valores de uma pessoa, mediante tratamento desrespeitoso, inconveniente e ofensivo à dignidade humana.
Alguns autores destacam-se na contribuição ao entendimento do AM a partir da ótica psicológica. Dentre eles, podemos citar: Leymann (1996), Hirigoyen (2002a, 2002b), Poilpot-Rocaboy (2003), Pedroso et al. (2006).

Para Leymann (1996), o AM corresponde a uma violência moral, em geral de cunho psicológico e não físico, evidenciada de forma bastante sutil e dissimulada, mas intencional, que, em geral, provoca estresse psicossocial na pessoa agredida. É considerada uma ação desprovida de ética, sistemática e com alto potencial de exclusão.

Para Hirigoyen (2002a, 2002b), AM é toda e qualquer atitude, ação ou conduta abusiva, identificada por uma diferenciação comportamental por parte do agressor, que age com palavras, atos e gestos agressivos, que podem vir a causar danos à personalidade, à dignidade ou à integridade física do assediado.

Poilpot-Rocaboy (2003) indica que o AM é materializado na recorrência ou repetição dos atos, ou seja, em atitudes duradouras. Os objetivos básicos do assediador consistem na intimidação, na desvalorização e no isolamento das vítimas, de forma a causar algum tipo de desestabilização emocional. Tal desestabilização pode ter consequências diversas, como a condução para estados de distração, a perda de poder, a perda de benefícios e até mesmo a demissão.

Um ponto de convergência em relação ao conceito de AM entre Leymann (1996), PoilpotRocaboy (2003) e Hirigoyen (2002b) é a prática sistemática, ou seja, repetitiva, habitual e continuada. O AM desestabiliza a vítima, constrange-a, humilha-a, causa-lhe danos, na maioria das vezes psicológicos, que podem levá-la a desistir do trabalho. Contudo, esses mesmos autores divergem, ainda que em parte, em relação a se os danos seriam meramente psicossociais ou também físicos, ou mesmo se os atos não seriam apenas ofensas à dignidade, e se seriam ou não deliberados.

Vale ressaltar que o AM constitui-se em um ato ilícito no âmbito civil ou trabalhista. Nesse sentido, Rodrigues Pinto (2006) argumenta que se trata de um dano moral decorrente da violação de alguns valores humanos fundamentais relacionados ao patrimônio imaterial do 
assediado. Assim, mesmo que não atingindo a higidez psíquica da vítima, a mera imposição ao assediado de situações de humilhação e vexame diminutivos da dignidade humana já sujeitaria o agressor à responsabilização pela reparação do dano. Seguindo esse entendimento, Pamplona Filho (2006) esclarece que a manifestação de doença psíquico-emocional não é elemento essencial para a caracterização do AM, mas sim a violação do direito da personalidade.

Em resumo, o AM deve possuir os seguintes elementos caracterizadores: a) sujeitos, sendo o assediador e o assediado; b) a conduta, referindose aos comportamentos ou atos atentatórios aos direitos da personalidade; c) reiteração e sistematização da conduta; e d) consciência do agente, ou seja, do assediador (ALKIMIN, 2006).

\subsection{Tipos de Assédio Moral}

De acordo com Hirigoyen (2002a), o AM pode ser classificado em quatro tipos: a) horizontal, quando ocorre entre pessoas de mesmo nível hierárquico; b) vertical ascendente, no qual um superior hierárquico é assediado por subordinados ou pessoas de um nível hierárquico inferior, sofrendo discordância ou retaliação; c) misto, quando ocorre tanto o AM horizontal quanto o AM vertical ascendente; e d) vertical descendente, quando um indivíduo em posição hierárquica superior assedia subordinados ou pessoas de nível hierárquico inferior. Na visão dessa autora, o AM misto, em geral, começa como um assédio horizontal, que culmina em AM vertical ascendente, em razão da omissão do superior hierárquico.

Rezende (2006: 122) também discorre sobre categorias de AM, seguindo a lógica elaborada por Hirigoyen (2002b), contudo enfatiza apenas três grupos. O primeiro é o AM vertical, praticado pelo empregador ou superior hierárquico, ainda que este não ocupe essa posição de maneira formal. O segundo é o AM ascendente, quando um empregado ou colega em posição hierárquica inferior assedia seu superior. E o terceiro é o AM horizontal, praticado entre colegas de serviço ou pessoas do mesmo escalão.

O perfil dos agressores também é bastante diversificado, em grande parte apresentando algum tipo de problema psíquico. Fields (2005 apud PEDROSO et al., 2006) agrupou quatro tipos primários: a) aqueles que buscam atenção; b) os que "querem ser" (destaque do autor); c) os gurus; e d) os sociopatas. A influência do uso de drogas e o histórico de vida do agressor também são aspectos relevantes, como destacam Pedroso et al. (2006).

De uma forma geral, Hirigoyen (2002a) destaca sete formas distintas de AM: a) recusa à comunicação direta; b) o ato de desqualificar; c) o ato de desacreditar; d) o ato de isolar; e) o ato de vexar; f) a indução ao erro; e g) o assédio sexual. Ressalta-se que o assédio sexual é considerado um dos tipos de AM porque, em geral, inicia-se como um AM e evolui para o assédio sexual quando os desejos do agressor não são atendidos pela vítima (FREITAS, 2001; BARRETO, 2005).

Outras ações, como culpar uma pessoa por erros profissionais, submeter a vítima a acusações ou insinuações maldosas, impor certo isolamento à vítima, desconsiderar o trabalho da pessoa, impor à vítima condições de trabalho insalubres, estabelecer tratamento desigual entre pares, infligir agressões diretas ou humilhar pessoas também são ações, formas ou instrumentos de AM (SANTOS, 2005).

Outros autores, como Leymann (1996), detalharam inúmeras ações que podem ser consideradas como AM. Isso, de certa forma, caracteriza o AM como um conceito "frouxo", no qual cabem muitas conceituações. Existe, porem, uma conexão entre as ações relacionadas na literatura, a saber: a ação deliberada e sistemática por parte de um agressor com o intuito de colocar a vítima em situação desfavorável.

Em instituições de ensino, o assédio moral começou a ser pesquisado com o trabalho de Olweus (1978), citado por Farrington (1993), denominado Agressão nas escolas (tradução nossa). A partir daí, passou a ser tema pesquisado com maior frequência, principalmente por pesquisadores norte-americanos (MUNTHE, 1989; O'MOORE, 1991; MELLOR, 1991; THOMAS, 2005).

Ainda no ambiente acadêmico, tratando-se especificamente da relação entre alunos e professores, apesar de escassas as pesquisas com esse recorte, pode-se verificar a prática de assédio por ambas as partes: o AM do aluno para com o professor, ou seja, quando o aluno assume o papel 
de agressor, sendo o professor a vítima; e o AM do professor para com o aluno, quando o aluno é a vítima e o professor é o assediador. O AM vertical descendente (professor-aluno) é bastante comum, em razão das características particulares do sistema de ensino do país. Para Almeida, Lagemann e Araújo (2007) e Buendía (2003), mesmo não havendo uma relação hierárquica como a existente entre chefes e empregados de empresas, o corpo docente da instituição assume uma posição superior em relação ao aluno. Isso ocorre porque os docentes têm a anuência da instituição de ensino para o repasse do conhecimento.

Em pesquisa realizada com professores de uma universidade estadual Paulista, Caran (2007) verificou que aproximadamente $41 \%$ dos professores afirmaram já terem sido vítimas de algum tipo de AM por parte de seus superiores; desse total, aproximadamente $60 \%$ já havia presenciado colegas sendo vítimas de AM. Das situações de AM descritas pelos professores, cerca de $15 \%$ referiam-se a algum tipo de pressão do superior para que o professor não aderisse a uma reforma curricular, ameaças à legitimidade no cargo, desistência de concurso por intimidação de membro da banca, pressão em caso de concursos para ingresso, pressão dos orientadores sobre orientandos e imposição de cargos e atividades a colegas menos titulados sem seu respectivo consentimento ou aceitação.

Categorias de AM descendente (professoraluno), ou seja, do professor (agressor) para com o aluno (vítima), foram apresentadas por Dela Coleta e Miranda Neto (2003). Os autores citam onze categorias: a) agressão física; b) agressão verbal aos alunos; c) ameaça aos alunos; d) acusação agressiva e sem provas; e) assédio sexual; comentários depreciativos, preconceituosos ou indecorosos; f) tratamento discriminatório e excludente; g) rebaixamento da capacidade cognitiva dos alunos; h) desinteresse e omissão; i) uso inadequado de instrumentos pedagógicos, com prejuízos aos alunos; j) recusa em realizar o trabalho; e $\quad k$ ) abandono do trabalho em sala de aula.

$\mathrm{O}$ número de alunos que relataram casos de humilhação envolvendo professores foi significativo na pesquisa realizada por Dela Coleta e Miranda Neto (2003). Corroborando os resultados dessa pesquisa, Caran (2007) destaca que muitos professores constrangem e humilham os discentes. A autora ressalta, porém, que esse tipo de comportamento pode ser reflexo de questionamentos por parte dos alunos, ou seja, um ato de defesa, ainda que não justificável.

Paixão, Santos e Martins Filho (2009) pesquisaram o AM aluno-professor em faculdades e universidades do país, independentemente do tipo de curso. O estudo, de base quantitativa, envolveu a análise de nove categorias de AM, a saber: agressão verbal, recusa em realizar atividades, desinteresse e omissão, rebaixamento da capacidade cognitiva, tratamento discriminatório, comentários depreciativos, assédio sexual, acusação agressiva e sem provas e ameaça por parte do aluno. Essas categorias foram, em grande parte, adaptadas a partir do trabalho de Dela Coleta e Miranda Neto (2003). Os resultados encontrados indicam que a recusa em fazer atividades propostas e o abandono da sala de aula são os tipos de AM mais constantes na direção aluno-professor. Os autores também concluíram que quanto maior o tempo de docência (experiência) do professor, menor é a ocorrência desses dois tipos de AM.

\section{METODOLOGIA}

\subsection{Descrição da Técnica Discurso do Sujeito Coletivo}

Em algumas abordagens científicas pretendese saber o que uma pessoa ou um grupo pensa. Para isso, é preciso motivar os sujeitos a expressar seus pensamentos, ou seja, a construir discursos, o que, quando é feito por meio de questões abertas, traz resultados mais fidedignos. Isso porque questões fechadas, ao trazerem respostas preconcebidas, não oferecem margem para reflexão senão sobre o que ali está colocado, substituindo, assim, a formação de um discurso próprio pela adequação a um discurso já existente.

A partir das respostas obtidas com as questões abertas, somam-se os discursos individuais naquilo que eles apresentam em comum, a fim de que expressem o pensamento de uma coletividade. Ressalta-se que os indivíduos cujos discursos serão analisados devem ser, de alguma forma, representativos em relação ao todo, a fim de que realmente reflitam a coletividade da qual fazem 
parte, embora tais resultados não possam ser generalizados.

É a partir desses pressupostos que foi desenvolvida, por volta dos anos 90, na Universidade de São Paulo (USP), a estratégia metodológica denominada Discurso do Sujeito Coletivo (DSC). A proposta, que tomou corpo a partir de meados de 2000, foi feita pelos pesquisadores Fernando Lefrève e Ana Maria Cavalcanti Lefrève e tem sido testada desde então, com maior incidência na área da saúde, campo de origem da técnica.

O DSC é uma técnica de organização de dados discursivos em pesquisas qualitativas que permite recuperar uma amostra de representações sobre um determinado tema em um dado universo. Em outras palavras, o DSC é uma proposta que busca harmonizar informações comuns em discursos individuais diferentes, reconstruindo-os por meio de uma soma capaz de refleti-los em um pensamento coletivo, dotado de especificidades semânticas que lhes diferenciem de outros tantos discursos.

Em linhas gerais, a técnica consiste basicamente em a) selecionar o essencial do conteúdo de cada depoimento; b) associar esses conteúdos a uma descrição de sentidos; c) agrupar os depoimentos em categorias; d) reunir os depoimentos de uma mesma categoria em um discurso único redigido na primeira pessoa do singular (LEFÈVRE, F.; LEFÈVRE, A. M., 2006).

Quanto à sua construção, o DSC é composto de algumas figuras metodológicas. A primeira é revelada pelas Expressões-Chave (E-Ch), trechos do discurso transcritos de forma literal. Em geral, as Expressões-Chave trazem a essência do depoimento.

O segundo grupo de figuras metodológicas é o das Ideias Centrais (IC). Uma IC é a descrição do sentido de um depoimento ou de um conjunto de depoimentos. Deve ser sintética, precisa e fidedigna ao descrever o sentido dos discursos.

O terceiro grupo é a ancoragem (AC). Esta é a manifestação explícita de uma teoria, ideologia ou crença, e pode ser também entendida como uma afirmação genérica usada para enquadrar uma situação específica. Pode-se dizer que quase todos os discursos têm uma ancoragem, pois são baseados em pressupostos, teorias, conceitos e hipóteses. O primeiro passo para construir esta figura é identificar marcas linguísticas evidentes, o que demanda uma análise subjetiva por parte do pesquisador, a qual pode acarretar o risco de uma escolha arbitrária e enviesada daquilo que se acredita ser a dita ancoragem (LEFÈVRE, F.; LEFÈVRE, A. M., 2006).

Por fim, chega-se ao discurso do sujeito coletivo, um discurso-síntese composto das expressões-chave que têm a mesma ideia central ou ancoragem.

A técnica vem sendo sistematicamente testada, segundo Lefèvre, F. e Lefèvre, A.M. (2006), em diversos tipos de pesquisa, o que reforçaria a crença em sua eficácia em registrar e expressar opiniões coletivas.

O DSC faz uso de um viés qualiquantitativo e tem como uma de suas propostas ser uma narrativa da quantidade (LEFÈVRE, F.; LEFÈVRE, A. M., 2006). Isso significa que, apesar de o DSC constituir-se originalmente como uma estratégia qualitativa, seu uso é totalmente conciliável com pesquisas quantitativas.

De acordo com seus criadores, a técnica do DSC resgata as opiniões por meio do discurso coletado em questões abertas, de maneira a facilitar a livre expressão do entrevistado. Todavia, os próprios autores afirmam que qualquer material apresentado de forma textual oral ou escrita - pode, em geral, servir de base para uso da técnica.

Cabe ressaltar que a técnica não é matemática nem metalinguística. Trata-se de uma soma qualificada, que agrega as expressões-chave de respostas semelhantes de indivíduos distintos. Sendo assim, um DSC consiste no produto dessas respostas semelhantes reunidas, compondo uma determinada opinião coletiva "virtual", a qual, por ser artificial, conforma outro discurso e consequentemente outra qualidade (LEFÈVRE, F.; LEFÈVRE, A. M., 2006:25).

De acordo com esses autores, segundo várias teorias sociológicas, especialmente a Teoria da Representação Social, os sujeitos que vivem numa mesma sociedade ou em sociedades similares pensam com base em um conjunto de representações ou Matrizes Discursivas comuns, embora com conteúdos e argumentos 
diferenciados. Por esse motivo, buscando respeitar o equilíbrio entre o comum e o especial, tem-se no discurso do sujeito coletivo a mesma opinião dita de modos distintos, mas complementares (LEFÈVRE, F.; LEFÈVRE, A. M., 2006).

Ressalta-se, porém, que a técnica não tem a pretensão de generalizar os resultados obtidos, embora seja possível fazê-lo mediante validação estatística adequada. No que diz respeito ao total da amostra para pesquisas com DSC, não existe, segundo os autores, um número mínimo necessário, razão pela qual tal decisão deve partir do bom senso. Inicialmente, em pesquisas que não consistem em generalizações, os autores recomendam, em linhas gerais, de dez a vinte pessoas/entrevistas, como base para a construção de um DSC.

A utilização do DSC como método de pesquisa, conforme Lefèvre, F. e Lefèvre, A. M. (2006), ocorre desde 1990, mas se destacou a partir de 2005, após seu amadurecimento. Uma análise do Banco de Dados do DSC do Instituto de Pesquisas do Discurso do Sujeito Coletivo IPDSC - apontou 735 registros em 10 de dezembro de 2008, 440 deles a partir de 2005, o que demonstra um crescimento de sua utilização, que, ainda que predominante no campo das Ciências da Saúde, área na qual a técnica se originou, já aparece em trabalhos nas áreas de Ciências Humanas e Sociais Aplicadas.

\subsection{Procedimentos Metodológicos}

Foram elaborados dois instrumentos de coleta de dados, no formato de um questionário com questões abertas (redação livre); apenas uma parte de um dos instrumentos forneceu os dados analisados na pesquisa. Os demais dados formaram uma base de dados que será utilizada em análises futuras, compondo um escopo de pesquisa mais amplo. Cada um dos dois questionários (A e B) continha três questões de resposta livre, nas quais os professores eram convidados a expressar, com base na experiência vivida, sua percepção a respeito do assédio moral do aluno para com o professor. Um mesmo professor poderia responder a ambos os questionários, porém, para aumentar o índice de respostas, o envio foi feito a grupos diferentes. Neste artigo serão analisadas, qualitativa e quantitativamente, de acordo com a metodologia do Discurso do Sujeito Coletivo (DSC), apenas as respostas relativas à pergunta: o que você entende por assédio moral (AM) na relação alunoprofessor, isto é, assédio do aluno ao professor?

Ademais, ambos os questionários também continham campos para coleta de informações básicas dos respondentes, opcionais, sem necessidade de identificação pessoal, como: vínculo institucional (instituição pública ou privada), escolaridade, gênero, idade e experiência (em anos) como professor.

Os questionários foram enviados aos respondentes por correio eletrônico (e-mail). O público-alvo foi formado por professores universitários, sem qualquer tipo de distinção (seja de curso, escolaridade, unidade federativa ou tipo de vínculo). $\mathrm{O}$ envio dos questionários foi direcionado, prioritariamente, aos professores de programas de pós-graduação stricto sensu da rede de contatos dos autores, com a solicitação de que fossem repassados aos contatos dos participantes dos cursos. As respostas foram obtidas num prazo previamente estipulado de 30 dias. Os questionários devolvidos fora do prazo estabelecido não foram considerados.

Conforme descrita por Lefèvre, F. e Lefèvre, A. M. (2003), a técnica do DSC consiste em um conjunto de procedimentos de tabulação e organização de dados discursivos provenientes, em geral, de depoimentos orais. Todavia, os próprios autores destacam que qualquer material apresentado de forma textual pode constituir a base para uso da técnica. Na presente pesquisa, foram utilizados depoimentos provenientes de 51 questionários respondidos. Após um procedimento de tratamento do material da pesquisa, nove questionários foram descartados por apresentarem vícios, isto é, respostas muito técnicas, com citações e textos não espontâneos ou incoerentes com a questão. Restaram 42 questionários a serem analisados, o que representa uma taxa de aproveitamento de respostas de aproximadamente $82 \%$.

Para a criação dos DSCs, foram executadas as seguintes operações a partir dos discursos coletados, utilizando-se o software MS Excel:

I. Seleção das Expressões-Chave (E-Ch) de cada discurso. Cada expressão-chave, segmentos, contínuos ou descontínuos, de discurso, revela o cerne das respostas; 
II. Identificação da Ideia Central (IC) de cada uma das expressões-chave selecionadas no passo anterior. Uma IC é a síntese do conteúdo das E$\mathrm{Ch}$, ou seja, seu significado real (embora algumas vezes oculto no discurso). Foram identificadas as ideias centrais semelhantes ou complementares, criando-se "etiquetas" (A, B, C, etc.) que identificavam os grupos de ICs (IC-A, IC-B, ICC, etc.);

III.Reunião das expressões-chave, ligadas às ideias centrais semelhantes ou complementares, em um discurso síntese que é o discurso do sujeito coletivo (DSC) propriamente dito. A discursividade, peça fundamental do DSC, foi mantida.

Cabe ressaltar que o caráter quantitativo foi devido ao agrupamento das E-Ch nas ICs, e que para as ICs que apresentaram mais expressõeschave foram criados os discursos coletivos. $\mathrm{O}$ caráter qualitativo decorreu da forma de construção dos discursos e de sua análise. Apesar de esta ser uma pesquisa qualiquantitativa, não se pretendeu realizar generalizações a partir dos resultados obtidos.

Convém salientar que as ideias centrais que não tiveram discursos apresentados não foram consideradas, necessariamente, menos relevantes que as demais. Apenas foram evidenciadas com menor frequência para esse grupo de respondentes.

Conforme preconizado pelo método, houve a necessidade de efetuar uma 'limpeza' de trechos que caracterizavam particularidades do discurso individual (nomes próprios, situações específicas, etc.); e, de modo que apresentassem uma estrutura sequencial clara e coerente, os discursos foram encadeados narrativamente, ou seja, os componentes do DSC foram ligados por elementos textuais (conjunções, pronomes, artigos, etc.) sem modificação do conteúdo (significado) original.

É importante destacar que a técnica original prevê a possibilidade de elaboração dos DSCs a partir de outros operadores metodológicos, as ancoragens (AC), que são a manifestação explícita de uma teoria, ideologia ou crença; podem ser também entendidas como uma afirmação genérica usada para enquadrar uma situação específica, mas não foram utilizadas no presente artigo por se entender que não agregariam elementos à análise.

Segundo Teixeira e Lefèvre (2008), o DSC representa um método que torna mais claras e expressivas as representações sociais, permitindo que um determinado grupo social (neste artigo, os professores universitários) possa ser visto como autor e emissor de discursos comuns, não necessariamente concordantes, mas complementares.

A análise dos resultados, demonstrada a seguir, foi realizada com base na revisão de literatura apresentada anteriormente.

\section{ANÁLISE DOS RESULTADOS}

As informações complementares presentes nos instrumentos de coleta permitiram levantar algumas informações acerca dos 42 respondentes da questão analisada. A maioria era do gênero masculino (61,9\%), enquanto $38,1 \%$ dos respondentes era do gênero feminino. $\mathrm{O}$ nível de escolaridade foi dividido entre 2 respondentes com superior completo $(4,76 \%), 5$ com especialização $(11,9 \%), 28$ com mestrado $(66,67 \%)$ e 7 com doutorado (16,67\%). Com relação ao vínculo institucional, a maior parte dos respondentes possuía vínculo com universidades públicas, sendo $21(50 \%$ do total $)$ de âmbito federal e $2(4,76 \%)$ de âmbito estadual. Os demais, 19 respondentes $(45,24 \%)$, possuíam vínculo com instituições privadas.

$\mathrm{Na}$ Tabela 1 pode-se visualizar que a maior parte dos respondentes tinha entre 30 e 39 anos de idade. A ampliação do intervalo entre as classes de idade permite concluir que mais de $80 \%$ dos participantes da pesquisa tinha entre 30 e 59 anos. 
Tabela 1 - Tabulação da idade dos respondentes (em anos)

\begin{tabular}{l|c|c}
\hline Entre 20 e 29 anos & 6 & $14,3 \%$ \\
\hline Entre 30 e 39 anos & 16 & $38,1 \%$ \\
\hline Entre 40 e 49 anos & 10 & $23,8 \%$ \\
\hline Entre 50 e 59 anos & 8 & $19,0 \%$ \\
\hline Acima de 60 anos & 2 & $4,8 \%$ \\
\hline Total & 42 & $100,0 \%$ \\
\hline \multicolumn{2}{r}{ Fonte: Elaboração própria. }
\end{tabular}

A maior parte dos respondentes apresentou tempo de experiência entre 6 e 10 anos, o que representa cerca de $36 \%$ dos respondentes. A ampliação do intervalo da classe de frequência para entre 1 e 10 anos possibilita abarcar aproximadamente $\quad 67 \%$ dos respondentes. Ademais, ressalta-se que professores com mais de 21 anos de atividade docente representaram 19\% do total.

Tabela 2 - Tabulação da experiência como professor dos respondentes (em anos)

\begin{tabular}{l|r|r}
\hline Entre 1 e 5 anos & 13 & $31,0 \%$ \\
\hline Entre 6 e 10 anos & 15 & $35,7 \%$ \\
\hline Entre 11 e 15 anos & 4 & $9,5 \%$ \\
\hline Entre 16 e 20 anos & 2 & $4,8 \%$ \\
\hline Acima de 21 anos & 8 & $19,0 \%$ \\
\hline Total & 42 & $100,0 \%$ \\
\hline
\end{tabular}

Fonte: Elaboração própria.

O tratamento quantitativo do material coletado limitou-se à análise da frequência com que os discursos individuais eram classificados de acordo com as Ideias Centrais (IC). Como uma única resposta poderia conter mais de uma IC, o somatório da frequência das ideias centrais foi superior à quantidade de respostas obtidas válidas
(42). Foram identificadas nove ICs distintas para a questão relativa ao entendimento do $\mathrm{AM}$ na relação aluno-professor. Suas respectivas frequências podem ser observadas no Quadro1 organizado de forma decrescente de frequência absoluta.

Quadro 1 - Frequência por Ideia Central

\begin{tabular}{|c|l|c|c|}
\hline \multirow{2}{*}{ Categoria } & \multicolumn{1}{|c|}{ Ideia Central } & $\begin{array}{c}\text { Frequência } \\
\text { Absoluta }\end{array}$ & $\begin{array}{c}\text { Frequência } \\
\text { Relativa } \\
\text { Cumulativa }\end{array}$ \\
\hline IC-A & Constrangimento ao professor & 15 & $23,8 \%$ \\
\hline IC-C & Pressão para obter vantagens & 12 & $42,9 \%$ \\
\hline IC-D & Falta de respeito por parte do aluno & 10 & $58,7 \%$ \\
\hline IC-B & Condutas difamatórias recorrentes & 7 & $69,8 \%$ \\
\hline IC-G & Obstáculos ao propósito da docência & 7 & $81,0 \%$ \\
\hline IC-F & Ameaça à integridade moral e física & 6 & $90,5 \%$ \\
\hline
\end{tabular}




\begin{tabular}{|c|l|c|c|c|}
\hline IC-E & $\begin{array}{l}\text { Ação coercitiva baseada na relação cliente- } \\
\text { fornecedor }\end{array}$ & 3 & $95,2 \%$ \\
\hline IC-H & Assédio sexual & 2 & $98,4 \%$ \\
\hline IC-I & Invasão de privacidade e intimidade & 1 & $100,0 \%$ \\
\hline
\end{tabular}

Fonte: Elaboração própria.

As ICs selecionadas (A, C, D, B, G e F) representaram conjuntamente pouco mais de $90 \%$ das ideias centrais contidas nos discursos dos respondentes, e foram escolhidas para análise mais detalhada e construção dos DSCs justamente pelo quesito representatividade.
Inicialmente, são tecidas considerações por IC; complementarmente, é feita a análise geral.

No Quadro 2 é apresentado o DSC, de acordo com o entendimento de AM do aluno para com o professor, no que tange à IC-A.

Quadro 2 - IC-A

\begin{tabular}{|l|}
\hline Ideia Central \\
\hline Constrangimento ao professor \\
\hline Discurso do Sujeito Coletivo \\
\hline É qualquer atitude do aluno que de alguma forma cause constrangimento ao professor, ou seja, uma \\
posição ou discurso que o aluno utilize de forma a intimidar o professor em seu ambiente de trabalho. É \\
falta de respeito com o professor, na frente de todos os alunos, quando o aluno constrange ou ofende \\
verbalmente o professor, querendo impor por coação psicológica, de pressão até gritos, a sua ideia, \\
deixando-o em uma situação delicada. Também pode ser por uma situação de humilhação do aluno para \\
com o professor, colocando o professor numa situação constrangedora, através de gestos, palavras, atos, \\
pela escrita ou mesmo por roupas ou posturas que tentam deixar o professor "sem graça". O professor, de \\
certa forma, se sente acuado ou intimidado no desempenho de suas funções - o aluno ridiculariza o \\
professor sobre qualquer motivo. Em síntese, situaçães humilhantes e constrangedoras, repetitivas e \\
prolongadas, como tentativa ou ato efetivo de humilhação direcionado ao professor em público.
\end{tabular}

Fonte: Elaboração própria.

O constrangimento ao professor é apontado no Quadro 2 como importante componente do AM, o que vai ao encontro das afirmações de Santos (2005). Percebe-se pelo DSC que a humilhação pública e deliberada recebe destaque como fator potencialmente limitador das atividades de docência. A repetição desse tipo de atitude de maneira prolongada é importante para a caracterização do assédio moral, conforme Poilpot-Rocaboy (2003). Destaca-se também a variedade de formas que esse constrangimento pode assumir, indo de palavras e gestos até o uso de posturas consideradas pelos professores como humilhantes. 
Quadro 3 - IC-C

\begin{tabular}{|l|}
\hline Ideia Central \\
\hline Pressão para obter vantagens \\
\hline Discurso do Sujeito Coletivo \\
\hline Consiste na pressão psicológica que o aluno exerce quando deseja obter algum benefício fora das normas \\
da IES e dos critérios estabelecidos pelo professor, ou seja, conseguir benefícios que deveriam ser \\
obtidos através de méritos educacionais. O aluno tenta conseguir barganhar pontuação complementar, \\
intimidar o docente no atendimento de conveniências de caráter pessoal, insinuações a respeito de que \\
faria qualquer coisa para passar na matéria, enfim, qualquer procedimento para ter facilidades na \\
obtenção de notas, ou melhor, livrar-se de reprovação. Insinuação de obter facilidades para aprovação \\
sem mérito, obter uma relação que satisfaça a interesses do aluno em detrimento da ética profissional do \\
professor. Insinuar uma possível troca de favores em detrimento da ética profissional. Quando há pressão \\
por resultado positivo, independente da realização de esforço natural por parte do aluno para alcançá-lo. \\
Trata-se de um comportamento ou atitude do aluno que vai além do que é socialmente aceito, adentrando \\
as questões de interesses pessoais, de forma a levar o professor a favorecer alguma solicitação do aluno. \\
O aluno ameaça o professor por não concordar com as notas das avaliações - falar que vai à coordenação \\
ou diretoria -, caracterizando coação ao professor para obter notas, frequência e aprovação. \\
\hline
\end{tabular}

\section{Fonte: Elaboração própria.}

A pressão para obter vantagens é caracterizada por uma conduta forçosa por parte do aluno em relação ao professor, que muitas vezes se sente impelido a agir ou a ter uma atuação diferente do que considera eticamente profissional. Por meio do DSC apresentado no Quadro 3, pode-se perceber a pressão individualizada, egoísta, imediatista e inconsequente por parte do aluno, que julga haver um benefício em obter méritos sem o devido merecimento, quando, na verdade, numa ótica de longo prazo, ele pode ser bastante prejudicado, haja vista que o esforço acadêmico faz parte do amadurecimento profissional e intelectual. Esse comportamento tangencia os valores acadêmicos presentes em algumas instituições tidas como clientelistas. Trata-se de uma ação completamente desprovida de ética e com alto poder de exclusão, conforme destaca Leymann (1996). 


\section{Quadro 4 - IC-D}

\begin{tabular}{|l|}
\hline Ideia Central \\
\hline Falta de respeito por parte do aluno \\
\hline Discurso do Sujeito Coletivo \\
\hline Trata-se da falta de respeito, de educação por parte do aluno para com o professor dentro e fora de sala, \\
de modo que interfira na relação entre ambas as partes no que tange ao desempenho e estados mentais. \\
Em outras palavras, o aluno sistematicamente se utiliza de comportamentos que ultrapassam o limite do \\
respeito para com o professor. É uma atitude de desdém do aluno às aulas ou ao docente. É um \\
comportamento desrespeitoso de forma repetitiva. É um abuso da relação, trato ofensivo, desacato ou \\
intolerância por parte do aluno. Um comportamento desequilibrado e não sadio no respeito e na \\
educação.
\end{tabular}

Fonte: Elaboração própria.

Percebe-se, por meio do discurso dos professores apresentado no Quadro 4, que o assédio moral também se constitui em frequentes atitudes desrespeitosas do aluno para com o professor, confirmando as afirmações de Santos (2005). A falta de respeito sistemática, o trato ofensivo, o desacato e a intolerância para com o professor também podem ser provenientes dos novos valores que permeiam a educação superior, os quais menosprezam e desvalorizam o papel do professor e supervalorizam a concepção do alunocliente que não pode mais ser contrariado sob qualquer hipótese, pois ele é a fonte de lucro da instituição.

\section{Quadro 5 - IC-B}

\begin{tabular}{|l|}
\hline Ideia Central \\
\hline Condutas difamatórias recorrentes \\
\hline Discurso do Sujeito Coletivo \\
\hline Constituem-se em condutas que atinjam o professor direta ou indiretamente, tais como a difamação, o \\
espalhar boatos e a colocação de apelidos. Quando a conduta se repete certo número de vezes. São \\
também ameaças que colocam em risco a integridade moral. Comentários maliciosos sobre a conduta do \\
professor, principalmente quando o professor atribui nota baixa ao aluno. Falsas acusações. Comentários \\
depreciativos sobre características físicas, financeiras ou intelectuais, colocando a imagem do professor \\
em situação de risco. Desqualificação e desmoralização do professor. Quando o professor é tachado de \\
atrasado, que não sabe nada, etc.
\end{tabular}

\section{Fonte: Elaboração própria.}

No DSC apresentado no Quadro 5 percebe-se claramente o assédio moral sendo compreendido a partir de recorrentes condutas difamatórias. Nesse caso, o AM assume um nível de gravidade ainda maior. Além da promoção do desrespeito, os professores sinalizam que o AM também acontece todas as vezes que os alunos criam comentários maliciosos, falsas acusações e boatos, difamando o professor e colocando sua imagem em situação de risco. Os professores afirmam que esse tipo de atitude surge, sobretudo, quando eles atribuem notas baixas aos alunos. Essa descrição do sujeito coletivo está associada a uma violência moral que gera estresse psicossocial na vítima e alto potencial de exclusão, conforme advoga Leymann (1996). 
Quadro 6 - IC-G

\begin{tabular}{|l|}
\hline Ideia Central \\
\hline Obstáculos ao propósito da docência \\
\hline Discurso do Sujeito Coletivo \\
\hline O aluno querer impor ao professor a didática e a avaliação que este último deve adotar, a utilização de \\
conversas paralelas, com respostas estúpidas e/ou indelicadas, o mau comportamento em sala, falta de \\
empenho nos trabalhos, negligenciar atividades não as levando à sério, tratar com desdém, o aluno \\
importunar o professor com questões impertinentes, descabidas, sem propósitos, querendo chamar a \\
atenção para si, enfim, esforços para prejudicar, atrapalhar e evitar colaboração e integração dele e do \\
grupo ao ambiente de ensino estabelecido pelo professor. São atitudes que quebram a relação de autoridade \\
do professor sobre a preservação do ambiente de estudo e sobre os formatos de procedimentos pedagógicos \\
e avaliativos. \\
\hline
\end{tabular}

Fonte: Elaboração própria.

O obstáculo à docência materializa-se toda vez que o aluno, isoladamente ou em grupo, age de forma a desestabilizar, desestruturar, atrapalhar ou mesmo impedir uma ação pedagógica por parte do professor. No DSC apresentado no Quadro 6, percebem-se atitudes que revelam uma completa falta de respeito para com o docente, além de um elevado grau de imaturidade do agressor. $\mathrm{O}$ professor tem sua autoridade questionada e, por vezes, quebrada, o que prejudica a conservação do ambiente de aprendizagem. Tal tipo de AM encontra suporte na conduta abusiva, na intimidação, na desvalorização do professor e em sua desestabilização psicológica, como discutido por Poilpot-Rocaboy (2003) e Hirigoyen (2002b).

\section{Quadro 7 - IC-F}

\begin{tabular}{|l|}
\hline Ideia Central \\
\hline Ameaça à integridade moral e física \\
\hline Discurso do Sujeito Coletivo \\
\hline Qualquer forma intimidatória exercida pelo aluno para com o professor por meio de comportamento que \\
visa sua desestabilização emocional e moral, por meio de ameaças ou tentativas de agressões físicas, e \\
que coloque em risco a integridade moral ou física do professor. Por exemplo: o aluno ameaça \\
fisicamente o professor dentro da sala de aula ao ouvido de todos, ainda que não realize. \\
\hline
\end{tabular}

Fonte: Elaboração própria.

A ameaça à integridade moral e física é destacada no DSC do Quadro 7 como caracterizadora do AM. Percebe-se que, para os professores, a mera possibilidade de agressão é suficiente para a desestabilização psicológica, não sendo necessária a consumação do ato de violência. A partir das afirmações de Hirigoyen (2002a), pode-se inferir que isso seria suficiente para causar danos à personalidade ou à dignidade, caracterizando-se, assim, o assédio moral.
Os DSCs construídos a partir da análise das respostas dos professores universitários participantes contêm uma ligação entre si e também uma relação aproximada com as categorias de AM apontadas por Paixão, Santos e Martins Filho (2009) na relação aluno-professor. A IC referente aos obstáculos ao propósito da docência tem relação com os tipos identificados como recusa em realizar atividades, desinteresse e omissão. $\mathrm{O}$ constrangimento ao professor, identificado pela IC-A, está associado ao 
rebaixamento da capacidade cognitiva do professor e também ao tratamento discriminatório. A IC ligada às condutas difamatórias recorrentes encontra eco nos tipos de AM nomeados de comentários depreciativos e acusação agressiva e sem provas. A ameaça à integridade moral e física (IC-F) pode ser representada na pesquisa desses autores como uma ameaça por parte do aluno ou uma agressão verbal. O assédio sexual é um tipo de AM identicamente observado em ambas as pesquisas, mesmo não tendo sido observada representatividade nesta.

Algumas ICs verificadas nesta pesquisa não possuem correspondência direta com os tipos de
AM levantados por Paixão, Santos e Martins Filho (2009). A IC pressão para obter vantagens é um desses casos. Contudo, poder-se-ia inferir que o conteúdo desta IC permearia a ameaça por parte do aluno, assim como a IC referente à ação coercitiva baseada na relação cliente-fornecedor. A IC invasão de privacidade e intimidade poderia estar associada ao tratamento discriminatório identificado por esses autores, porém não há evidências claras nesse sentido. E a IC referente à falta de respeito por parte do aluno encontra eco em quase todos os tipos levantados pelos pesquisadores citados, razão pela qual foi apresentada de forma isolada no Quadro 8.

Quadro 8 - Comparativo dos tipos de AM na relação aluno-professor

\begin{tabular}{|c|c|}
\hline $\begin{array}{l}\text { Tipos de AM apontados por Paixão, Santos e Martins } \\
\qquad(2009)\end{array}$ & Tipos de AM obtidos nos DSCs \\
\hline Recusa em realizar atividades & \multirow{2}{*}{ Obstáculos ao propósito da docência } \\
\hline Desinteresse e omissão & \\
\hline Rebaixamento da capacidade cognitiva & \multirow{2}{*}{ Constrangimento ao professor } \\
\hline Tratamento discriminatório & \\
\hline Comentários depreciativos & \multirow{2}{*}{ Condutas difamatórias recorrentes } \\
\hline Acusação agressiva e sem provas & \\
\hline Ameaça por parte do aluno & \multirow{2}{*}{ Ameaça à integridade moral e física } \\
\hline Agressão verbal & \\
\hline Assédio sexual & Assédio sexual \\
\hline & Pressão para obter vantagens \\
\hline & Falta de respeito por parte do aluno \\
\hline & Ação coercitiva baseada na relação cliente-fornecedor \\
\hline & Invasão de privacidade e intimidade \\
\hline
\end{tabular}

Fonte: Elaboração própria.

Vale ressaltar que as três ICs (IC-E, IC-H e ICI) não tiveram seus respectivos DSCs construídos em função de sua representatividade nas respostas. $\mathrm{O}$ fato de terem aparecido em menor número não significa que o grau de importância do ato de assédio moral foi menor. É certo que uma ação coercitiva por parte do aluno baseada numa pseudorrelação de clientelismo, assédio sexual ou invasão de privacidade configura um tipo de AM grave, porém menos evidenciado nos respondentes desta pesquisa.

\section{CONSIDERAÇÕES FINAIS}

O propósito desta pesquisa foi buscar compreender o constructo assédio moral do aluno para com o professor. Para isso, utilizou-se uma abordagem qualiquantitativa e, como estratégia metodológica, a análise do discurso do sujeito coletivo (DSC). A partir da análise do material empírico coletado, chegou-se a nove ideias centrais (ICs): 1) IC-A (Constrangimento ao professor); 2) IC-C (Pressão para obter vantagens); 3) IC-D (Falta de respeito por parte 
do aluno); 4) IC-B (Condutas difamatórias recorrentes); 5) IC-G (Obstáculos ao propósito da docência); 6) IC-F (Ameaça à integridade moral e física); 7) IC-E (Ação coercitiva baseada na relação cliente-fornecedor); 8) IC-H (Assédio sexual); 9) IC-I (Invasão de privacidade e intimidade). Das nove ICs, gerou-se o discurso coletivo das seis primeiras mencionadas, pois elas representam conjuntamente pouco mais de $90 \%$ das ideias centrais contidas nos discursos dos respondentes. Assim, foram selecionadas justamente pelo quesito representatividade.

Esta investigação insere-se em um trabalho de pesquisa mais amplo que busca analisar o assédio moral na relação aluno-professor. Buscou-se realizar um estudo qualiquantitativo e exploratório para mapear os fatores que caracterizam o assédio moral na direção aluno-professor. É essa, pois, a maior contribuição desta investigação, já que não são muitas as pesquisas sobre assédio moral que focam uma melhor compreensão deste constructo a partir do vetor discente-docente (PAIXÃO et al., 2013). Dito de outra forma, já existe um campo vasto de pesquisas que trabalham o constructo assédio moral (CARRIERI; AGUIAR; DINIZ, 2013) e assédio moral no trabalho (BENEVIDES et al., 2012), dentre outros, porém ainda são poucos os trabalhos que procuram explorar a compreensão do assédio moral ascendente, quando o aluno é o assediador de seu professor. Os DSCs construídos a partir da análise das respostas dos professores universitários são complementares e oferecem uma compreensão do que é o AM na visão dos professores, que são, nesta pesquisa, os que sofrem por causa de ações de constrangimento, pressão para obter vantagens, falta de respeito, condutas difamatórias recorrentes, dentre outras, por parte dos alunos.

As ICs que emergiram da fala dos respondentes contêm fortes relações com as categorias analíticas de outras pesquisas realizadas, sobretudo a de Paixão, Santos e Martins Filho (2009), sobre o assédio moral na relação aluno-professor.

Em relação aos fatores limitantes desta investigação, pode-se citar o público respondente. Nesse sentido, ampliar e diversificar mais a base de respondentes (em termos de idade, vínculo institucional, gênero e tempo de experiência como docente) podem trazer complementos importantes à análise teórico-empírica do fenômeno investigado.

$\mathrm{O}$ aprofundamento do entendimento desse constructo é importante, pois, dentre outros fatores, contribui para uma maior consciência e reflexão sobre condutas, atitudes e comportamentos que não são mais condizentes com o estágio evolutivo e de civilidade das sociedades modernas. Tais comportamentos são inaceitáveis em qualquer grupo social, sobretudo naqueles que são o lócus de formação de cidadãos socialmente responsáveis e eticamente íntegros.

Convém que pesquisas futuras sobre o tema busquem aprofundar o entendimento do AM na relação aluno-professor. Seria interessante, por exemplo, procurar entender o que motiva os alunos a agir de forma assediadora, isto é, os fatores que disparam uma atitude de assédio moral no vetor aluno-professor. Dito de outra forma, é relevante a discussão sobre os motivos que levam o aluno à prática de assédio moral, bem como sobre os malefícios desta para a instituição e o processo de aprendizagem. Essas investigações poderiam, até mesmo, contribuir com a minimização do assédio moral e permitir verificar se as instituições universitárias estão cumprindo seu papel educacional, social e moral. Ademais, uma nova frente de pesquisa poderia iniciar trabalhos que considerassem a visão oposta ao presente estudo, o AM do professor para com o aluno, um vasto território a ser desbravado.

\section{REFERÊNCIAS}

ALKIMIN, M. A. Assédio moral na relação de emprego. 2. ed. Curitiba: Juruá, 2006.

ALMEIDA, D. R.; LAGEMANN, L.; ARAÚJO, S. V. Assédio moral na percepção de professores de cursos de Administração: um estudo exploratório. In: ENCONTRO DE GESTÃO DE PESSOAS E RELAÇÕES DE TRABALHO, 1., 2007, Natal. Anais... Natal: ANPAD, 2007.

BARRETO, M. Assédio moral: a violência sutil. 2005. 198 f. Tese (Doutorado em Psicologia Social) - Pontifícia Universidade Católica de São Paulo, São Paulo, 2005.

BENEVIDES, Samira Daiha et al. Assédio moral no trabalho: um estudo exploratório no município 
de Fortaleza - Ceará. Rev. Adm. UFSM, Santa Maria, v. 5, n. 2, p. 373-385, maio/ago. 2012.

BUENDÍA, M. Radiografía del mobbing en el centro de studios. Boletín de notícias sobre acoso psicológico, nov. 2003. Disponível em: $<\mathrm{http}: / /$ www.mobbingopinion.bpweb.net/artman/p ublish/ article_793.shtml)>. Acesso em: $7 \mathrm{dez}$. 2008.

CARAN, V. C. S. Riscos psicossociais e o assédio moral no contexto acadêmico. 2007. 188 f. Dissertação (Mestrado em Enfermagem Fundamental) - Universidade de São Paulo, Ribeirão Preto, 2007.

CARRIERI, Alexandre de Pádua; AGUIAR, Ana Rosa Camillo; DINIZ, Ana Paula Rodrigues. Reflexões sobre o indivíduo desejante e o sofrimento no trabalho: o assédio moral, a violência simbólica e o movimento homossexual. Cad. EBAPE.BR, Rio de Janeiro, v. 11, n. 1, p. 165-180, mar. 2013.

DELA COLETA, J. A.; MIRANDA NETO, H. C. O rebaixamento cognitivo, aagressão verbal e outros constrangimentos e humilhações: o assédio moral na educação superior. In: REUNIÃO ANUAL DA ASSOCIAÇÃO NACIONAL DE PÓS-GRADUAÇÃO E PESQUISA EM EDUCAÇÃO, 26., 2003, Poços de Caldas. Anais... Poços de Caldas: ANPED, 2003.

FARRINGTON, D. P. Understanding and Preventing Bullying. Crime and Justice, v. 17, n. 3, p. 381-458, 1993. <http://dx.doi.org/10.1086/ 449217>.

FINK, L. D. The First Year of College Teaching. New Directions for Teaching and Learning, San Francisco, CA: Jossey Bass, v. 1984, n. 17, p. 1115, Mar. 1984.

FIUZA, C. Direito Civil: curso completo. Belo Horizonte: Del Rey, 2004.

FREITAS, M. E. Assédio moral e assédio sexual: faces do poder perverso nas organizações. Revista de Administração de Empresas, São Paulo, v. 41, n. 2, p. 8-19, abr./jun. 2001. <http://dx.doi.org/ 10.1590/S0034-75902001000200002>.
HIRIGOYEN, M. F. Assédio Moral: a violência perversa no cotidiano. 5. ed. Rio de Janeiro: Bertrand Brasil, 2002a.

HIRIGOYEN, M. F. Mal-estar no trabalho: redefinindo o assédio moral. Rio de Janeiro: Bertrand Brasil, 2002b.

LEFÈVRE, F.; LEFÈVRE A. M. O Discurso do Sujeito Coletivo: Um novo enfoque em pesquisa qualitativa - Desdobramentos. Caxias do Sul: Educs, 2003.

LEFÈVRE, F.; LEFÈVRE, A. M. O sujeito coletivo que fala. Revista Interface Comunicação, Saúde, Educação, v. 10, n. 20, p. 517-524, 2006.

LEYMANN, H. Content and development of moral harassment at work (mobbing). European Journal of Work and Organizational Phychology, v. 5, n. 2, p. 165-184, 1996. <http://dx.doi.org/ $10.1080 / 13594329608414853>$.

MELLOR, A. HelpingVictims. In: ELLIOTT, M. (Ed.) Bullying: A Practical Guide to Coping for Schools. Harlow: Longman, 1991.

MUNTHE, E. Bullying in Scandinavia. In: ROLAND, E.; MUNTHE, E. Bullying: An International Perspective, London: DavidFulton, 1989.

OLSEN, D.; SORCINELLI, M. D. The Pretenure Years: A Longitudinal Perspective. In: SORCINELli, M. D.; AUSTIN, A. E. (Org.). Developing New and Junior Faculty. San Francisco, CA: Jossey Bass, 1992.

OLWEUS, D. Aggressionin the Schools.Washington, D. C.: Hemisphere, 1978.

O'MOORE, A. M. What Do Teachers Need to Know. In: ELLIOTT, M. (Ed.). Bullying: A Practical Guide to Coping for Schools. Harlow: Longman, 1991.

PAIXÃO, R. B. et al. Por que ocorre? Como lidar? A percepção de professores de graduação em Administração sobre o assédio moral. Revista de Administração, São Paulo, v. 48, n. 3, p. 516529, jul./ago./set., 2013. 
PAIXÃO, R. B.; SANTOS, L. C.; MARTINS FILHO, L. N. Comportamentos negativos no contexto acadêmico: uma análise da relação professor-aluno. In: ENCONTRO DA ASSOCIAÇÃO NACIONAL DE PÓSGRADUAÇÃO E PESQUISA EM ADMINISTRAÇÃO, 33., 2009, São Paulo. Anais... São Paulo: ANPAD, 2009.

PAMPLONA FILHO, R. Noções conceituais sobre assédio moral na relação de emprego. Jus Navegandi, Teresina, ano 10, n. 1149, 2006. Disponível em: <http://jus2.uol.com.br/doutrina /texto.asp?id=8838>. Acesso em: 4 dez. 2008.

PEDROSO, V. G. et al. Aspectos conceituais de assédio moral: um estudo exploratório. RAS, v. 8, n. 33, p. 139-147, out./dez. 2006.

POILPOT-ROCABOY, G. Harcèlement moral dans le travail: Analyse du concept et role de la Gestion des Ressources Humaines. In: ALLOUCHE, J. Encyclopédie des ressources humaines. Paris: Vuibert, 2003.

REZENDE, L. O. A deteriorização das relações de poder dentro do organismo empresarial: uma análise do assédio moral no contrato de trabalho. 2006. 177 f. Dissertação (Mestrado em Direito) Setor de Ciências Jurídicas, Universidade Federal do Paraná, Curitiba, 2006.

RODRIGUES PINTO, J. A. O assédio moral nas relações de trabalho. 2006. Disponível em: $<$ www.prt18.mpt.gov.br/eventos/2006/preconceito/ Jose_Augusto_Rodrigues_Pinto_O_assedio_mora 1_nas_relacoes_de_trabalho.doc $>$. Acesso em: 7 dez. 2008.

SADLER, I. The Influence of Interactions with Students for the Development of New Academics as Teachers in Higher Education. The International Journal of Higher Education and Educational Planning, v. 64, n. 2, p. 147-160, 2012.

SANTOS, U. O. E. Assédio moral e a relação com o trabalho. 2005. Disponível em: $<$ www.uj.com.br/publicacoes/doutrinas/default.as $\mathrm{p}$ ? action $=$ doutrina\&iddoutrina $=2175>. \quad$ Acesso em: 7 dez. 2008.
SENNETT, R. A corrosão do caráter: conseqüências pessoais do trabalho no novo capitalismo. 14. ed. Rio de Janeiro: Record, 2009.

SORCINELLI, M. D. Effective Approaches to New Faculty Development. Journal of Counselling and Development, v. 72, n. 5, p. 474479, 1994. <http://dx.doi.org/10.1002/j.15566676.1994.tb00976.x>.

SORCINELLI, M. D.; AUSTIN, A. E. Educational developers: The multiple structures and influences that support our work. New Directions for Teaching and Learning, v. 2010, n. 122, p. 25-36, 2010. <http://dx.doi.org/10.1002/ tl.395>.

SOUZA-SILVA, J. C.; DAVEL, E. Concepções, Práticas e Desafios na Formação do Professor: Examinando o Caso do Ensino Superior de Administração no Brasil. Organizações $e$ Sociedade, v. 12, n. 35, p. 113-134, out./dez. 2005. <http://dx.doi.org/10.1590/S1984-9230200 $5000400007>$.

TEIXEIRA, J. J. V.; LEFÈVRE, F. Significado da intervenção médica e da fé religiosa para o paciente idoso com câncer. Ciência e Saúde Coletiva, v. 13, n. 4, p. 1247-1256, 2008. $<$ http://dx.doi.org/10.1590/S1413-812320080004 $00021>$.

THOMAS, M. Bullying among support staff in a higher education institution. Health Education, v. 105 , n. 4 , p. $273-288,2005$. <http://dx.doi.org/ $10.1108 / 09654280510602499>$.

TURNER, J. L.; BOICE, R. Starting at the beginning: concerns and needs of new faculty. To Improve the Academy, v. 6, p. 41-55, 1987.

VEGA, G.; COMER, D. R. Sticks and Stones may Break Your Bones, but Words can Break Your Spirit: Bullying in the Workplace. Journal of Business Ethics, v. 58, n. 1/3, p. 101-109, 2005. $<$ http://dx.doi.org/10.1007/s10551-005-1422-7>. 